\title{
Analysis of Fade Dynamic at Ku-Band in Malaysia
}

\author{
Siat Ling Jong, ${ }^{1,2}$ Michele D’Amico, ${ }^{3}$ Jafri Din, ${ }^{2}$ and Hong Yin Lam $^{2}$ \\ ${ }^{1}$ Department of Communication Engineering, Faculty of Electrical and Electronic Engineering, UTHM, \\ Batu Pahat, 86400 Johor, Malaysia \\ ${ }^{2}$ Department of Communication Engineering, Faculty of Electrical Engineering, UTM, Skudai, 81310 Johor, Malaysia \\ ${ }^{3}$ Dipartimento di Elettronica, Informazione e Bioingegneria, Politecnico di Milano, 20133 Milan, Italy
}

Correspondence should be addressed to Jafri Din; jafri@fke.utm.my

Received 11 September 2013; Revised 26 November 2013; Accepted 10 December 2013; Published 5 January 2014

Academic Editor: Stefano Selleri

Copyright (c) 2014 Siat Ling Jong et al. This is an open access article distributed under the Creative Commons Attribution License, which permits unrestricted use, distribution, and reproduction in any medium, provided the original work is properly cited.

This work investigates fade dynamics of satellite communication systems in equatorial heavy rain region based on a one year of Ku-band propagation measurement campaign carried out in Universiti Teknologi Malaysia (UTM), Johor, Malaysia. First order statistics of rain attenuation are deduced and the results are found to be in good agreement with those obtained from other beacon measurements gathered within the same area (Kuala Lumpur). Moreover, the fade duration and slope statistics of the satellite signal variations are also carefully derived and subsequently compared with the ITU-R recommendation model. Such information is useful for the system operator and radio communication engineer for the design of appropriate fade mitigation techniques as well as the quality of service that could be offered to the user (according to the time interval for a typical day). Further evaluation on the performances of several ITU-R models in the heavy rain region are needed based on the measurement database available of this climatic region.

\section{Introduction}

In satellite communication links, rain attenuation is the dominant impairment especially for frequency above $10 \mathrm{GHz}$ particularly in tropical and equatorial regions. Precipitation causes attenuation due to scattering and absorption of the electromagnetic energy and it leads to significant performance degradation. Consequently, Ku-band broadcasting services are affected by link outage especially during timecritical transmission such as real-time news and sport events. The probable duration of rain fade, the time of day when it is likely to occur, and how frequently it happens are all important aspects for the design of satellite services [1].

In order to make operation of the satellite systems feasible at frequencies above $10 \mathrm{GHz}$, appropriate Propagation Impairment Mitigation Techniques (PIMTs) are required such as power control, link diversity, and adaptive modulation scheme $[2,3]$. In general, the proper design and implementation of PIMTs require the knowledge of first and second order statistics of rain attenuation [4]. First order statistics refer to cumulative distribution of rain attenuation and rainfall rate while second order statistics describe the dynamic characteristics of rain attenuation such as fade duration, fade slope, and inter-fade-interval. Fade duration and fade slope are referred to the time interval between two successive crossings above the same attenuation threshold and to the rate of change of attenuation with time, respectively [5]. The knowledge of second order statistics for rain attenuation in a given environment is essential to help service providers to specify the type of modulation and error-correction schemes, the range of uplink power control, and the tracking speed of PIMTs that need to be used during severe rain periods to reduce the probability of link outages [4]. Up to the date, numbers of propagation measurement campaigns have been conducted at Ku-band temperate regions [6-8] while very limited investigations have been reported in heavy rain regions particularly focused on fade dynamics of rain attenuation statistics [1,9-11]. This work investigates such crucial statistics in an equatorial site by exploiting one year of slant path attenuation measurements at this frequency band.

This work aims at investigating the characteristics of rain attenuation at the first and second order statistics by exploiting the propagation measurement carried out at Universiti 


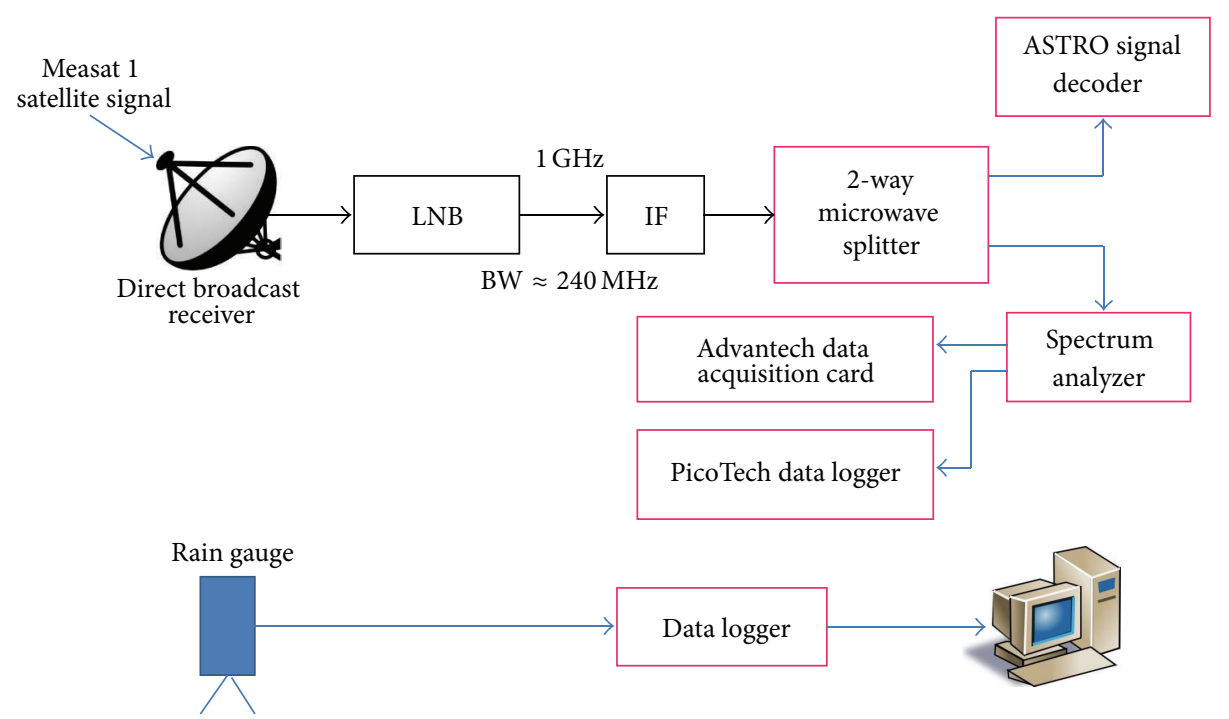

FIGURE 1: Block diagram of measurement set-up.

Teknologi Malaysia (UTM). Details of the experimental setup and data processing are described in Section 2. Section 3 focuses on the precipitation characteristic for tropical and equatorial regions. Afterwards, the statistics of attenuation are presented in Section 4. The core of the paper lies in Section 5, in which dynamic characteristics of rain attenuation, specifically fade duration and fade slope as well as their diurnal variation are presented. In addition, the comparisons are made to point out the differences between our experimental results and the previous works carried out in the same region. Several ITU-R recommendations have been included in the comparisons as well, since those models are considered as the reference models for the design of telecommunication system recommended by International Telecommunication Union. Finally, Section 6 draws some conclusions.

\section{Experimental Setup and Data Processing}

The station used for this experiment is located at Universiti Teknologi Malaysia (UTM) campus in Skudai, Johor, situated at $1.55^{\circ} \mathrm{N}$ and $103.64^{\circ} \mathrm{E}$. The receiver's antenna is pointed toward Malaysia MEASAT-1 broadcast satellite at $91.5^{\circ} \mathrm{E}$, with an elevation angle of $75.61^{\circ}$ and height above mean sea level of about $30 \mathrm{~m}$. The frequency is $11.075 \mathrm{GHz}$ (Ku-band) and the incoming wave is vertically polarized. During the recording period, the system experienced very few equipment downtimes and availability of the receiver achieved $96 \%$ from March 2001 to February 2002. The dynamic range of measurable attenuation level is approximately about $40 \mathrm{~dB}$.

The experimental setup block diagram is illustrated in Figure 1; the receiver was installed in an open area far away from the tall buildings or any other obstacle that could cause partial blockage of the first Fresnel Ellipsoid. Rainfall rate were measured by a tipping bucket rain gauge which is placed on the roof top of the TV Engineering Laboratory in Faculty of Electrical Engineering, UTM. The area around

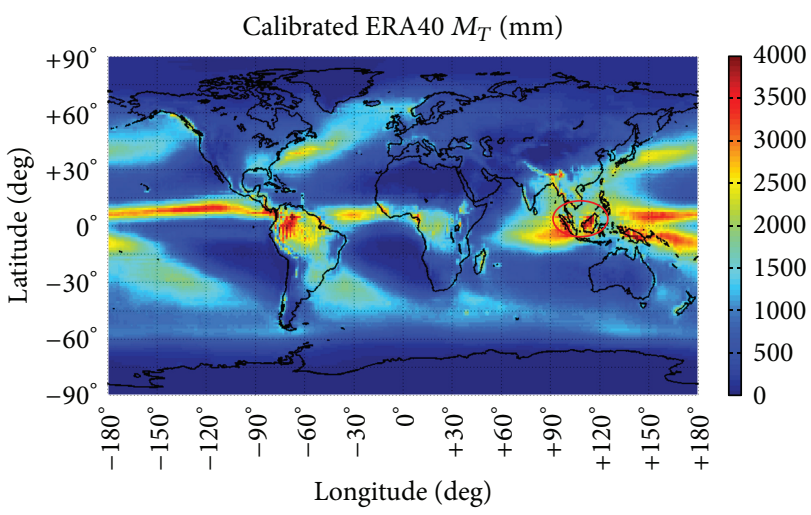

FIgURE 2: Mean annual rainfall map of the world for 40 years obtained from ECMWF databases [12]. The circle in the map refers to our location (equatorial Malaysia).

the rain gauge is kept clear from obstacles in order to avoid measurement biases due to the blockage. The integration time and resolution of the rain gauge is 1 minute and $0.2 \mathrm{~mm} / \mathrm{tip}$, respectively. The collected rain tips have been processed according to the procedures described in [13].

The raw data are recorded in the form of received signal level, and one sample-per-second is stored to be analyzed offline. Due to the absence of a radiometer, the attenuation zero reference level is carefully determined by averaging the samples 30 minute before and after a rain event, this last being identified from the observation of the rain rate time series concurrently gathered from the colocated rain gauge [9]. Subsequently, after the attenuation zero reference level is determined, the attenuation time series are calculated as the difference between the received signal level and the zero reference level. Next, a low pass filter (a 30 seconds moving average [7]) is applied to remove the rapid fluctuation components due to the tropospheric scintillation. 


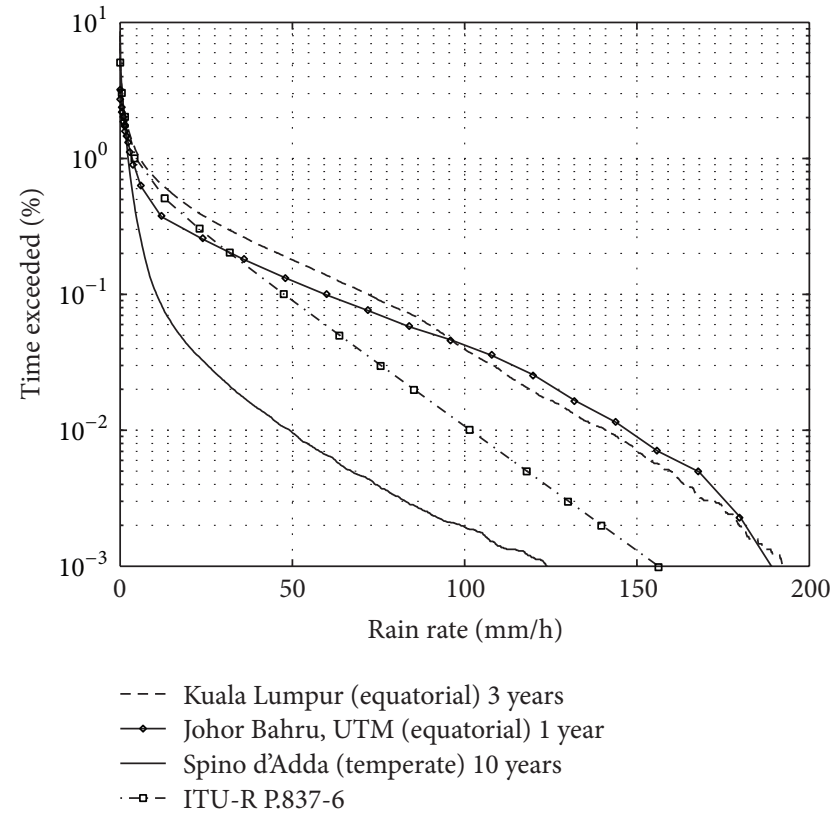

FIGURE 3: CCDFs of rainfall rate for three different locations and two climatic regions: Kuala Lumpur (1992-1994) equatorial, Johor Bahru, UTM, (2001) equatorial, and Spinod'Adda (1993-2002) temperate.

It is also worth mentioning that, during the period of the experiment, the equipment and the instruments are well maintained and periodically calibrated in order to avoid instrumental drifts and biases. RF chain variations due to temperature fluctuations and others propagation effects are also removed from the measured data during the preprocessing phase. Hence, by applying such procedures, the attenuation time series considered in this work are solely due to the rain effect.

\section{Statistics of Rain Rate}

It is well known that rain intensity appears as one of the important parameters for the design of microwave propagation link as this parameter directly influences the cumulative statistics of the rain attenuation. This work considered the data measured in UTM, Johor, which is located in the heavy rainfall equatorial region. Figure 2 clearly shows the presence of heavy rainfall in tropical and equatorial regions; the location relative to this work is marked by a circle. The 40 years of mean annual rainfall rate of the world is obtained from the European Centre for Medium-Range Weather Forecasts (ECMWF) databases [12]. This is further supported by the Complementary Cumulative Distribution Functions (CCDFs) of precipitation rate for different climatic conditions, shown in Figure 3. Kuala Lumpur and Johor BahruUTM are characterized by the tropical/equatorial climate, whereas Spinod'Adda, Italy, represents temperate regions. The good agreement between the KL and UTM curves gives a clear indication of the local climatic peculiarities within equatorial area. Even though the distance between these two

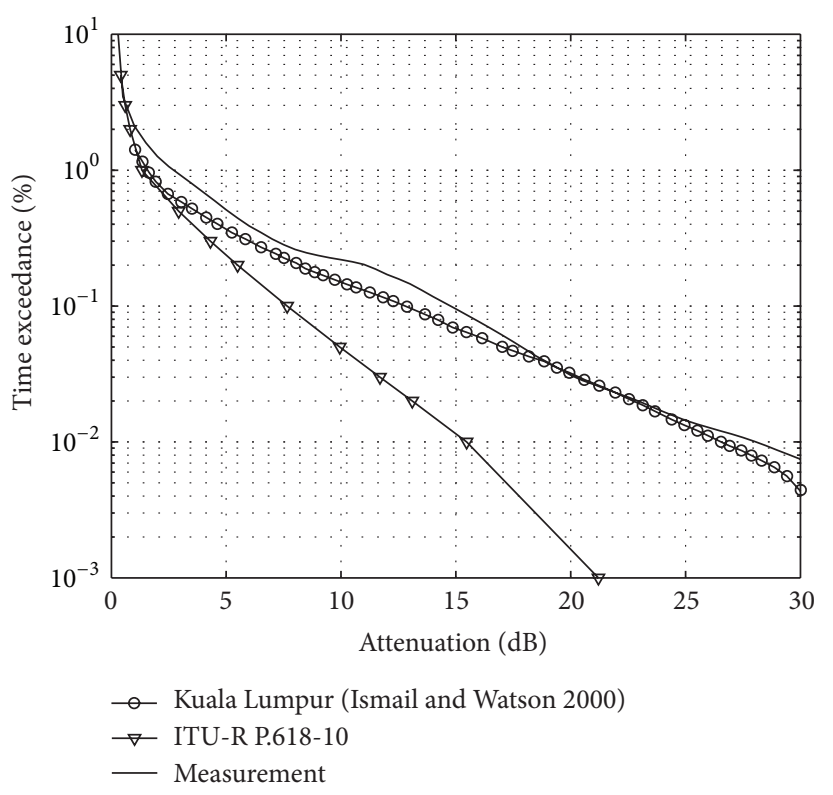

FIgURE 4: The cumulative distribution of attenuation.

locations is about $300 \mathrm{Km}$ and the statistics for UTM only consist of one year of data (compared to the three years disdrometer measurement in KL), it is clear that the CCDF is stable enough to correctly represent the precipitation characteristics of this region, that are remarkably different from those relative to Spinod'Adda.

In addition, the CCDF derived from the ITU-R P.837-6 [14] based on the location in Johor, UTM, are also shown in Figure 3 . We only observed a good fit up to the time percentage of $0.2 \%$ and after that, as the rain rate increases, there are quite significant difference between the measured rain rate and the ITU-R recommendation. Such result seems to point out that in the heavy rain region, ITU-R recommendation for the prediction of rain attenuation [15] are more likely to underestimate the measured statistics of rain attenuation.

\section{Statistics of Attenuation}

Satellite links operating at tropical and equatorial locations experience important propagation impairments due to precipitation. Time series of rain rate collected from rain-gauge measurements are insufficient to provide detailed information on rain attenuation, as the rainfall is measured at a location of interest and on the ground, whereas rain attenuation occurs along the whole propagation path crossing the troposphere. Therefore, it is important to gather direct measurements of attenuation by using the Earth terminal of a satellite link, as was done at UTM.

The first order statistics of attenuation CCDF for one year of measurements is shown in Figure 4, together with the prediction CCDF of ITU-R P.618-10 [15] as well as the beacon measured CCDF of Kuala Lumpur [10].

The measured attenuation in Johor followed closely the beacon CCDF result throughout the entire percentage of 
TABLE 1: Comparison of measured cumulative statistics of slant path attenuation.

\begin{tabular}{lcccc}
\hline \multirow{2}{*}{ Statistic } & \multicolumn{2}{c}{ Rain rate exceeded for specific \% of times } & \multicolumn{2}{c}{ Attenuation exceeded for specific \% of times } \\
& $0.1 \%$ & $0.01 \%$ & $0.1 \%$ & $0.01 \%$ \\
\hline UTM, Malaysia & $59.5 \mathrm{~mm} / \mathrm{h}$ & $147.3 \mathrm{~mm} / \mathrm{h}$ & $14.8 \mathrm{~dB}$ & $28 \mathrm{~dB}$ \\
Kuala Lumpur, Malaysia & $62 \mathrm{~mm} / \mathrm{h}$ & $169.4 \mathrm{~mm} / \mathrm{h}$ & $12.5 \mathrm{~dB}$ & $26.2 \mathrm{~dB}$ \\
\hline
\end{tabular}

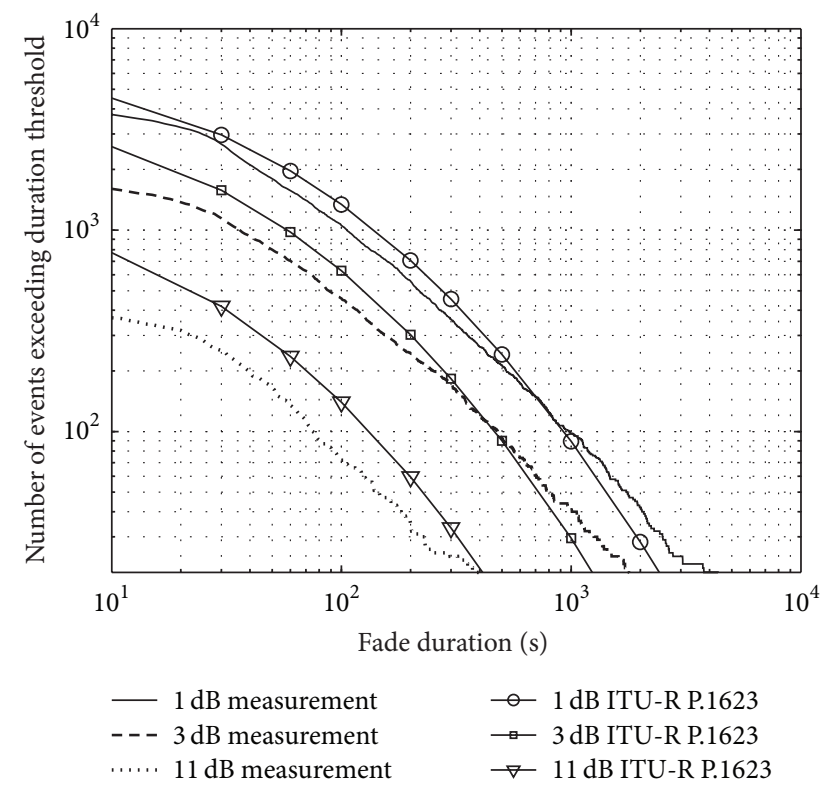

FIGURE 5: Number of fade events exceeding a given duration. The measurement results are compared with ITU-R P.1623 prediction model.

time, except some small discrepancy at the interval around $0.1 \%$ to $0.2 \%$. It is worthwhile mentioning that even if only one year of data are presented, at the lower time percentages there are enough samples to reliably reproduce the CCDF of rain attenuation. For example, at higher attenuation level (i.e., $30 \mathrm{~dB}$ ), there are 2334 samples from 10 rain events. On the other hand, ITU-R P.618-10 model underestimates the measured attenuation throughout the entire range of time. Significant differences can be found in the range $0.001 \%$ to $0.5 \%$ of time. Table 1 gives the comparison of measurement details.

\section{Dynamic of Attenuation}

This section focuses on the dynamic characteristics of attenuation, in particular fade duration and fade slope. Such information is of interest for the design of proper PIMTs toward the improvement of outage probability as well as the establishment of the prescribed Quality of Service (QoS).

5.1. Fade Duration. The effects of fades on the QoS perceived by the end user are very much conditioned by their duration [8]. Fade duration estimation is essential for the power control and error correction schemes such as forward error

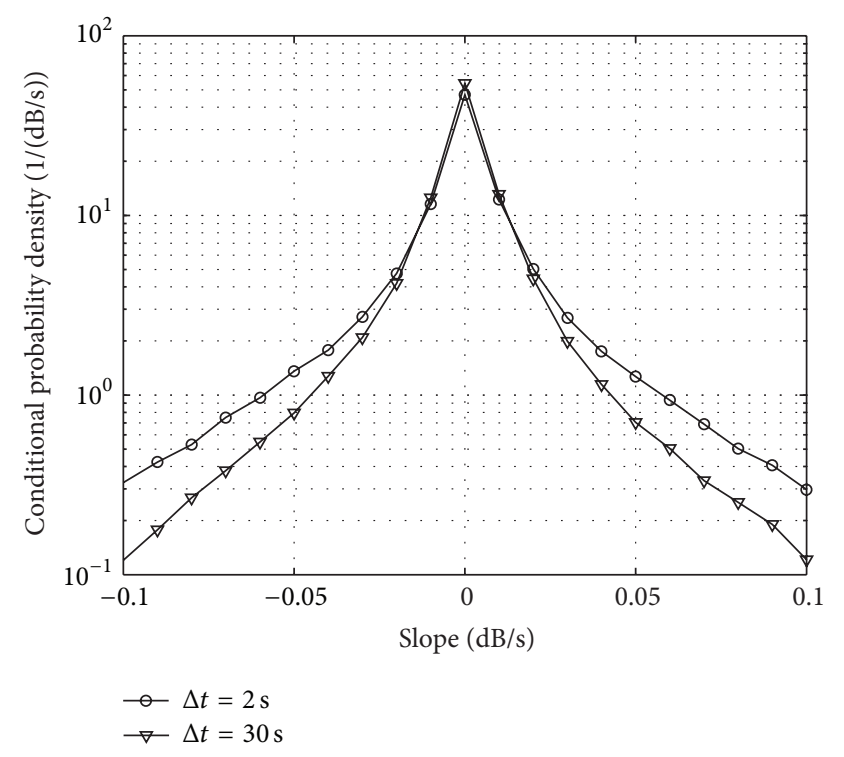

FIgURE 6: Conditional distribution of fade slope for $\Delta t=2 \mathrm{~s}$ and $\Delta t=30 \mathrm{~s}$ at $A=1 \mathrm{~dB}$.

correction techniques which reduce the effect of link outage $[5,16]$. The total number of fades for attenuation thresholds of 1,3 , and $11 \mathrm{~dB}$, plotted as a function of fade durations is shown in Figure 5.

There were 1600 events exceeding $10 \mathrm{~s}$ for $3 \mathrm{~dB}$ threshold in the experiment, but only 360 events were above $11 \mathrm{~dB} .450$ fades were more than $3 \mathrm{~dB}$ and $11 \mathrm{~dB}$ fades exceeded $100 \mathrm{~s}$. Such durations are sufficient to cause significant interruption to the services provided to the end users. For example, the operators of satellite broadcasting services at temperate regions usually consider $7 \mathrm{~dB}$ of attenuation as a typical margin for direct-to-home Ku-band satellite broadcasting services $[1,17]$. But such a margin might not be considered appropriate for equatorial regions, where this threshold is exceeded more frequently compared to the temperate areas.

In addition, these results are also compared with the recommendation ITU-R P.1623 [5]. It is found that ITU$\mathrm{R}$ model is in good agreement with the $1 \mathrm{~dB}$ measurement result. The distributions also have quite similar shape and trend for $3 \mathrm{~dB}$ and $11 \mathrm{~dB}$ thresholds up to about $1000 \mathrm{~s}$; above $1000 \mathrm{~s}$, the number of measured events is too low to draw any statistically sound conclusion.

Table 2 shows the number of events whose duration exceeds a given value, for different attenuation levels, and compares it with the result from the propagation measurement campaign [11] carried out in Penang, Malaysia $\left(5.35^{\circ} \mathrm{N}\right.$ 


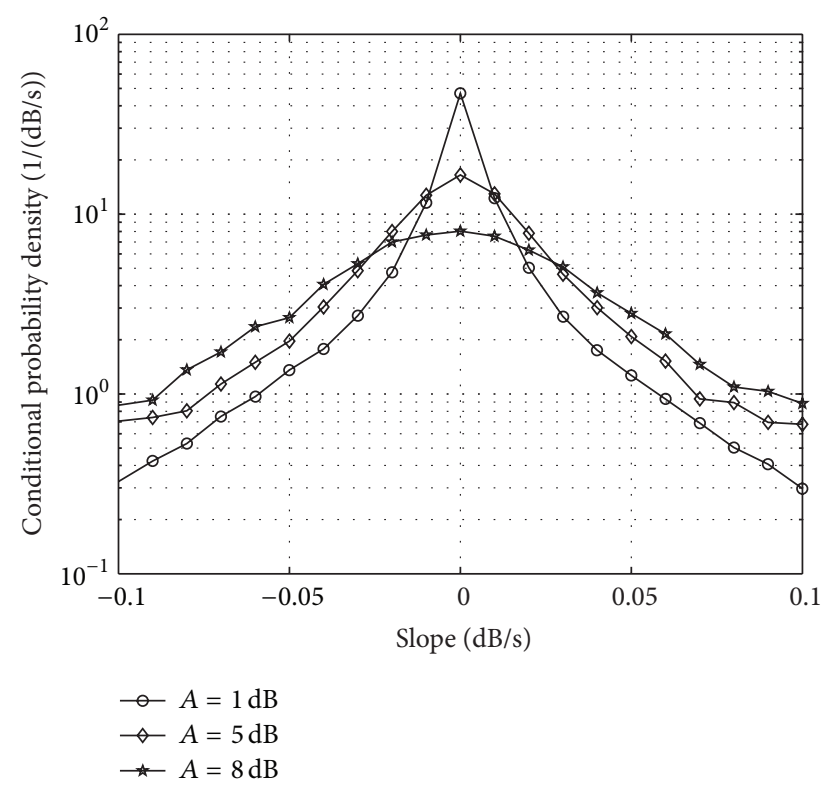

FIGURE 7: Conditional probability density of fade slope for various attenuation levels.

and $\left.100.3^{\circ} \mathrm{E}\right)$. As can be observed, the number of events collected at UTM is much higher than the number of fade events in Penang. However, it is worth noting that both results show that the numbers of events decrease as the attenuation level and the duration of fade increase. This is due to the fact that heavy rainfall events are often of short duration.

5.2. Fade Slope. Beside fade duration, fade slope is another significant parameter that impacts the minimum speed of the Uplink Power Control (ULPC) system. According to [6], fade slope, $\zeta$, is calculated as

$$
\varsigma(t)=\frac{A(t+0.5 \Delta t)-A(t-0.5 \Delta t)}{\Delta t}(\mathrm{~dB} / \mathrm{s}),
$$

where $A$ is attenuation and $\Delta t$ is the time interval length over which fade slope is calculated. It is important to use an appropriate time interval to calculate the fade slope; in particular, long time intervals may lead to miss out peaks of high attenuation, causing errors in the estimation of the slope [7]. Comparison of $1 \mathrm{~dB}$ threshold fade slope between $\Delta t=2 \mathrm{~s}$ and $\Delta t=30 \mathrm{~s}$ is presented in Figure 6.

The conditional probability density function (pdf) of $\zeta$ for $\Delta t=2 \mathrm{~s}$ is shown in Figure 7. The slope distributions represent the attenuation level of 1,5 , and $8 \mathrm{~dB}$. It is found that the distributions are symmetric around zero $\mathrm{dB} / \mathrm{s}$ for both positive and negative slopes. When the attenuation increases, the slope distribution becomes broader; this implies that the rate of change is faster than that for low attenuation, most probably due to the characteristics of strong convective events. In contrast, when attenuation is low, the distribution slope is sharp and peaked.

A comparison of $5 \mathrm{~dB}$ and $8 \mathrm{~dB}$ slope distributions with ITU-R P.1623 prediction model is shown in Figure 8.

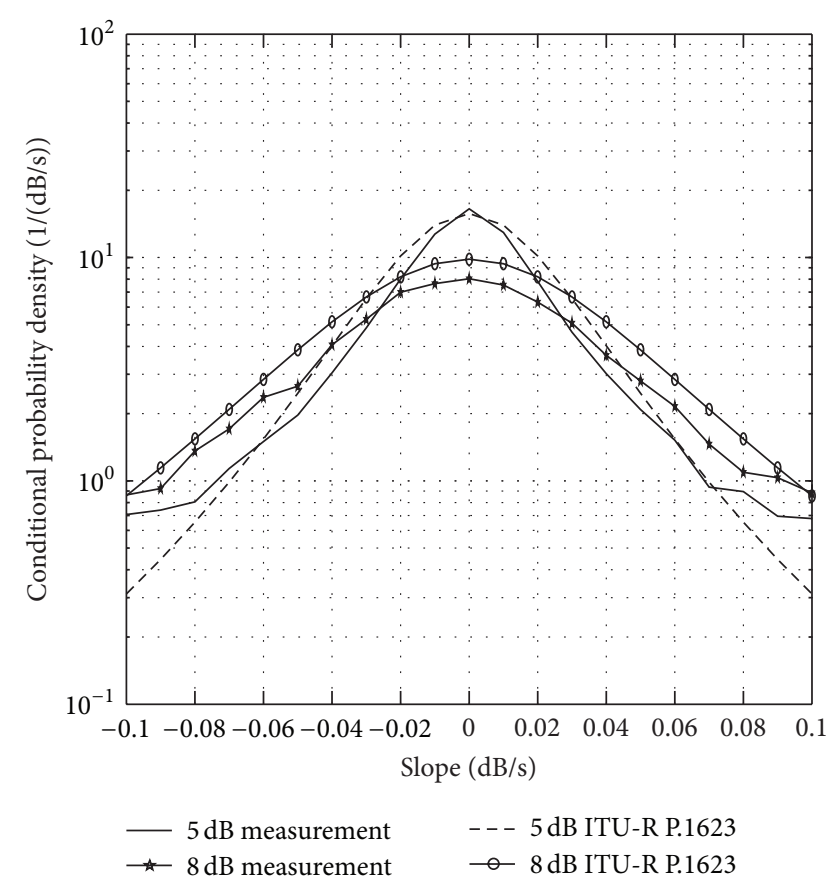

Figure 8: Comparison of fade slope between measurement and ITU-R prediction model for $A=5 \mathrm{~dB}$ and $A=8 \mathrm{~dB}$.

The ITU-R model appears to fit the measurement distribution fairly well; there is only a slight systematic overestimate of the rate of changes for a given level of conditional probability.

5.3. Diurnal Variation. Diurnal variation on the slant path attenuation is crucial especially for heavy rain regions which experience significantly different precipitation rate at different time of the day. This is particularly true for the equatorial Malaysia where the variations turned out to be quite substantial as evidenced in [18]. For this purpose, we evaluate diurnal variation for four time intervals: 00:00-06:00, 06:00-12:00, 12:00-18:00, and 18:00-24:00. Two attenuation thresholds for $3 \mathrm{~dB}$ and $7 \mathrm{~dB}$ are depicted, respectively, in Figure 9. Both results show that the most intense rain events occur in the afternoon from $12 \mathrm{pm}$ to $6 \mathrm{pm}$, when the sun has heated the ground and was uplifting to the air. Such information at the underlying time period gives important message to the service provider who needs to guarantee the QoS of the link services during this busiest business hours. Besides this, such fading at this period also may impact the prime-time of the broadcasting audience.

\section{Conclusions}

This work presents the results of a propagation measurement campaign carried out in equatorial Malaysia (heavy rain regime) at Ku-band. Key information of first and second order statistics (i.e., long term rain attenuation CCDF, fade duration, and fade slope) has been extracted and analyzed. 
TABLE 2: Number of events whose duration exceeds a given value, for different attenuation thresholds.

\begin{tabular}{|c|c|c|c|c|c|c|c|c|c|c|c|c|}
\hline \multirow{3}{*}{ Duration (s) } & \multicolumn{12}{|c|}{ Number of events } \\
\hline & \multicolumn{2}{|c|}{$1 \mathrm{~dB}$} & \multicolumn{2}{|c|}{$2 \mathrm{~dB}$} & \multicolumn{2}{|c|}{$4 \mathrm{~dB}$} & \multicolumn{2}{|c|}{$6 \mathrm{~dB}$} & \multicolumn{2}{|c|}{$8 \mathrm{~dB}$} & \multicolumn{2}{|c|}{$12 \mathrm{~dB}$} \\
\hline & Johor & Penang & Johor & Penang & Johor & Penang & Johor & Penang & Johor & Penang & Johor & Penang \\
\hline 60 & 1572 & 202 & 987 & 156 & 549 & 135 & 284 & 95 & 169 & 71 & 118 & 42 \\
\hline 300 & 361 & 105 & 220 & 43 & 107 & 34 & 49 & 19 & 21 & 14 & 18 & 9 \\
\hline 700 & 149 & 56 & 85 & 16 & 43 & 5 & 14 & 0 & 7 & 0 & 12 & 0 \\
\hline 1600 & 57 & 24 & 33 & 0 & 15 & 0 & 7 & 0 & 5 & 0 & 6 & 0 \\
\hline 2400 & 32 & 10 & 19 & 0 & 10 & 0 & 7 & 0 & 5 & 0 & 5 & 0 \\
\hline 3600 & 22 & 2 & 13 & 0 & 8 & 0 & 7 & 0 & 5 & 0 & 4 & 0 \\
\hline
\end{tabular}

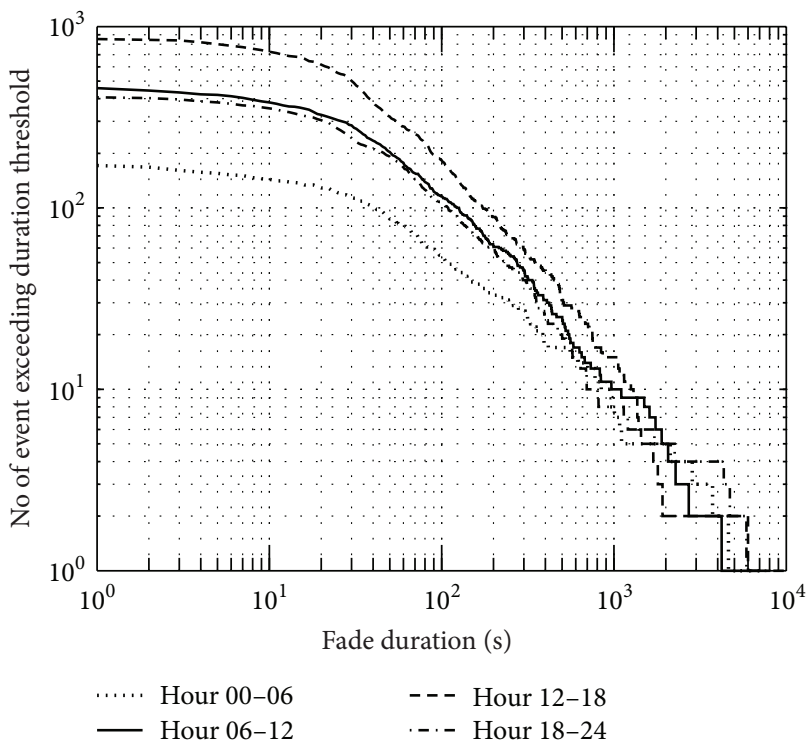

(a)

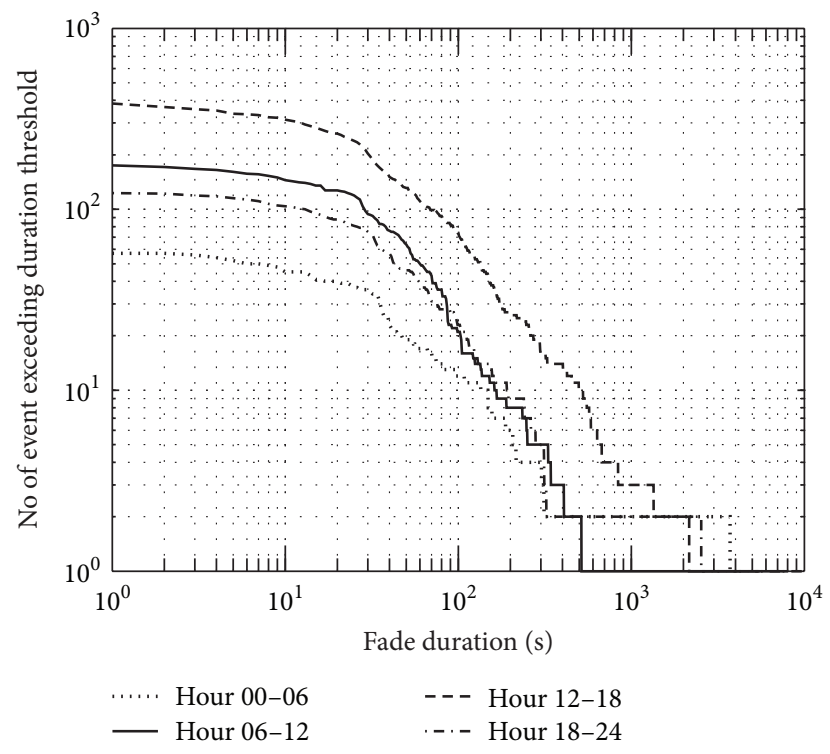

(b)

FIGURE 9: Diurnal variation for attenuation $3 \mathrm{~dB}$ (a) and $7 \mathrm{~dB}$ (b).

The results revealed the dynamic characteristics of fading with respect to the local rainfall peculiarity in this particular region. The first order statistics are found to be good agreement with another measured statistics from a satellite beacon receiver located in Kuala Lumpur, Malaysia. On the other hand the fade duration distribution depicts the same behavior as ITU-R prediction model while the slope distributions were found to be substantially symmetrical around $0 \mathrm{~dB} / \mathrm{s}$ and the conditional pdf of ITU-R which predicted fade slope follows closely the measurements. In addition, it is found that the highest rain-fade slope is likely to occur during evening hours (12 pm to $6 \mathrm{pm}$ ) due to the local convective events that frequently occur at this particular time. Such results provide critical information on the number and duration of outages as well as on system unavailability that together with the statistics of fade slope are useful for system designers to develop suitable PIMTs such as power control, adaptive modulation schemes, and diversity techniques to improve the link quality and availability especially during the heavy rain events in this particular region.

\section{Conflict of Interests}

The authors declare that there is no conflict of interests regarding the publication of this paper.

\section{Acknowledgment}

The authors are grateful for the Universiti Tun Hussein Onn Malaysia (UTHM) scholarship and UTM funded under “Research University Grant” Vot. no. Q.J130000.2523.04H10.

\section{References}

[1] J. E. Allnutt and F. Haidara, "Ku-band diurnal fade characteristics and fade event duration data from three, two-year, Earthspace radiometric experiments in equatorial Africa," International Journal of Satellite Communications, vol. 18, pp. 161-183, 2000.

[2] Q. W. Pan, J. E. Allnutt, and C. Tsui, "Evaluation of diversity and power control techniques for satellite communication systems 
in tropical and equatorial rain climates," IEEE Transactions on Antennas and Propagation, vol. 56, no. 10, pp. 3293-3301, 2008.

[3] A. D. Panagopoulos, P. M. Arapoglou, and P. G. Cottis, "Satellite communications at $\mathrm{Ku}, \mathrm{Ka}$ and $\mathrm{V}$ bands: propagation impairments and mitigation techniques," IEEE Communications Surveys \& Tutorials, vol. 6, no. 3, pp. 2-14, 2004.

[4] M. Cheffena and C. Amaya, "Prediction model of fade duration statistics for satellite links between 10-50 GHz," IEEE Antennas and Wireless Propagation Letters, vol. 7, pp. 260-263, 2008.

[5] ITU-R P. 1623-1, "Prediction method of fade dynamics on earth-space paths," International Telecommunications Union, Geneva, Switzerland, 2003.

[6] M. M. J. L. van de Kamp, "Statistical analysis of rain fade slope," IEEE Transactions on Antennas and Propagation, vol. 51, no. 8, pp. 1750-1759, 2003.

[7] F. F. Franklin, K. Fujisaki, and M. Tateiba, "Fade dynamics on earth-space paths at ku-band in Fukuoka, Japan fadeslope evaluation, comparison, and model," IEEE Antennas and Wireless Propagation Letters, vol. 5, no. 1, pp. 80-83, 2006.

[8] J. M. García-Rubia, J. M. Riera, P. García-Del-Pino, and A. Benarroch, "Propagation in the ka band: experimental characterization for satellite applications," IEEE Antennas and Propagation Magazine, vol. 53, no. 2, pp. 65-76, 2011.

[9] H. Dao, M. R. Islam, and K. A. S. Al-Khateeb, "Rain fade slope model in satellite path based on data measured in heavy rain zone," IEEE Antennas and Wireless Propagation Letters, vol. 12, pp. 50-53, 2013.

[10] A. F. Ismail and P. A. Watson, "Characteristics of fading and fade countermeasures on a satellite-Earth link operating in an equatorial climate, with reference to broadcast applications," IEE Proceedings, vol. 147, no. 5, pp. 369-373, 2000.

[11] J. S. Mandeep, "Fade duration statistics for Ku-band satellite links," Advances in Space Research, vol. 52, no. 3, pp. 445-450, 2013.

[12] ITU Study Group 3, "Fascicle concerning the rainfall rate model given in Annex 1 to Recommendation," ITU-R P. 837-6, International Telecommunication Union Radiocommunication, 2012.

[13] M. D'Amico, S. L. Jong, and C. Riva, "Tipping bucket data processing for propagation application," Electronics Letters, vol. 49, no. 8, pp. 569-571, 2013.

[14] ITU-R P. 837-5, "Characteristics of precipitation for propagation modeling," International Telecommunications Union, Geneva, Switzerland, 2007.

[15] ITU-R P. 618-10, "Propagation data and prediction methods required for the design of earth-space telecommunication systems," International Telecommunications Union, Geneva, Switzerland, 2009.

[16] F. F. Franklin, K. Fujisaki, and M. Tateiba, "Fade duration analysis on earth-space paths at Ku-band in Fukuoka, Japan," Electronics Letters, vol. 41, no. 25, pp. 5-6, 2005.

[17] U. Fiebig and C. Riva, "Impact of seasonal and diurnal variations on satellite system design in V band," IEEE Transactions on Antennas and Propagation, vol. 52, no. 4, pp. 923-932, 2004.

[18] H. Y. Lam, L. Luini, J. Din, C. Capsoni, and A. D. Panagopoulos, "Investigation of rain attenuation in equatorial Kuala Lumpur," IEEE Antennas and Wireless Propagation Letters, vol. 11, pp. 1002-1005, 2012. 

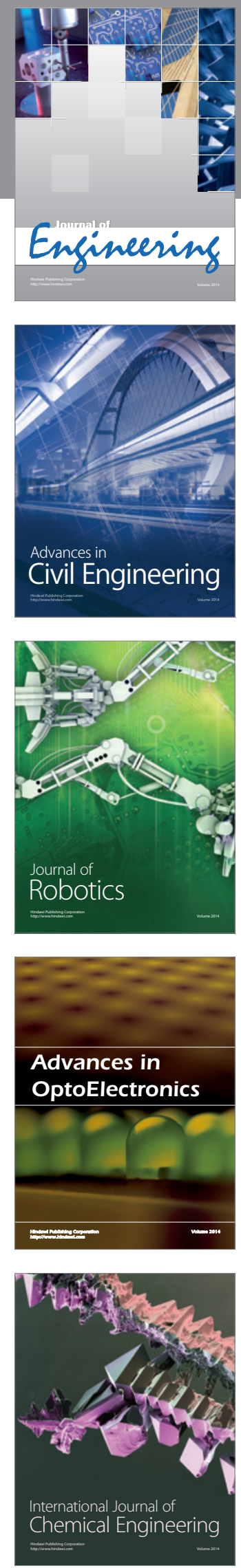

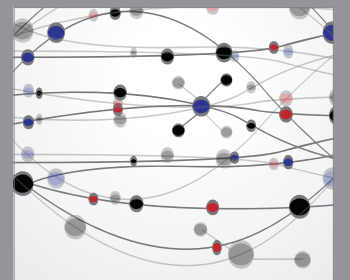

The Scientific World Journal
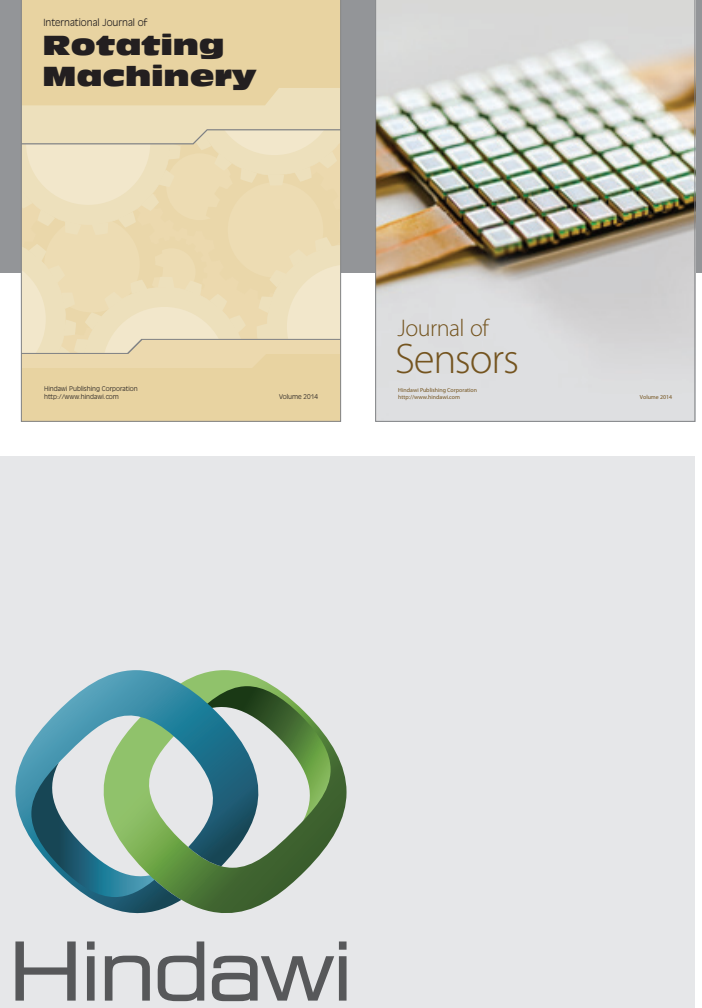

Submit your manuscripts at http://www.hindawi.com
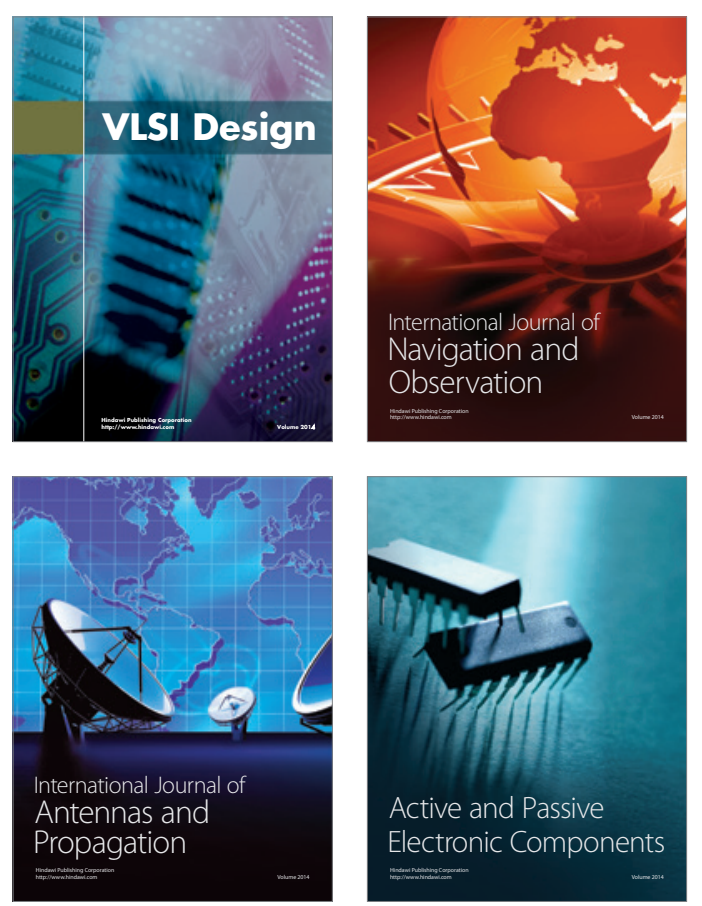
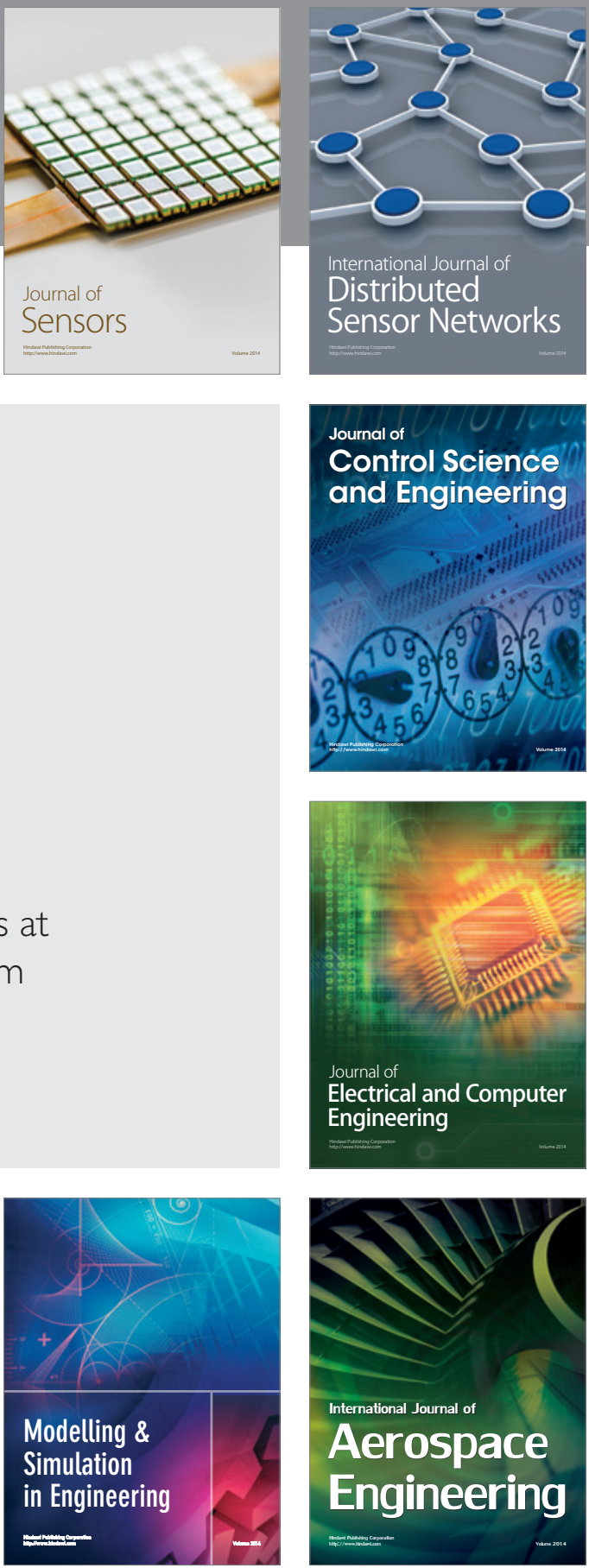

Journal of

Control Science

and Engineering
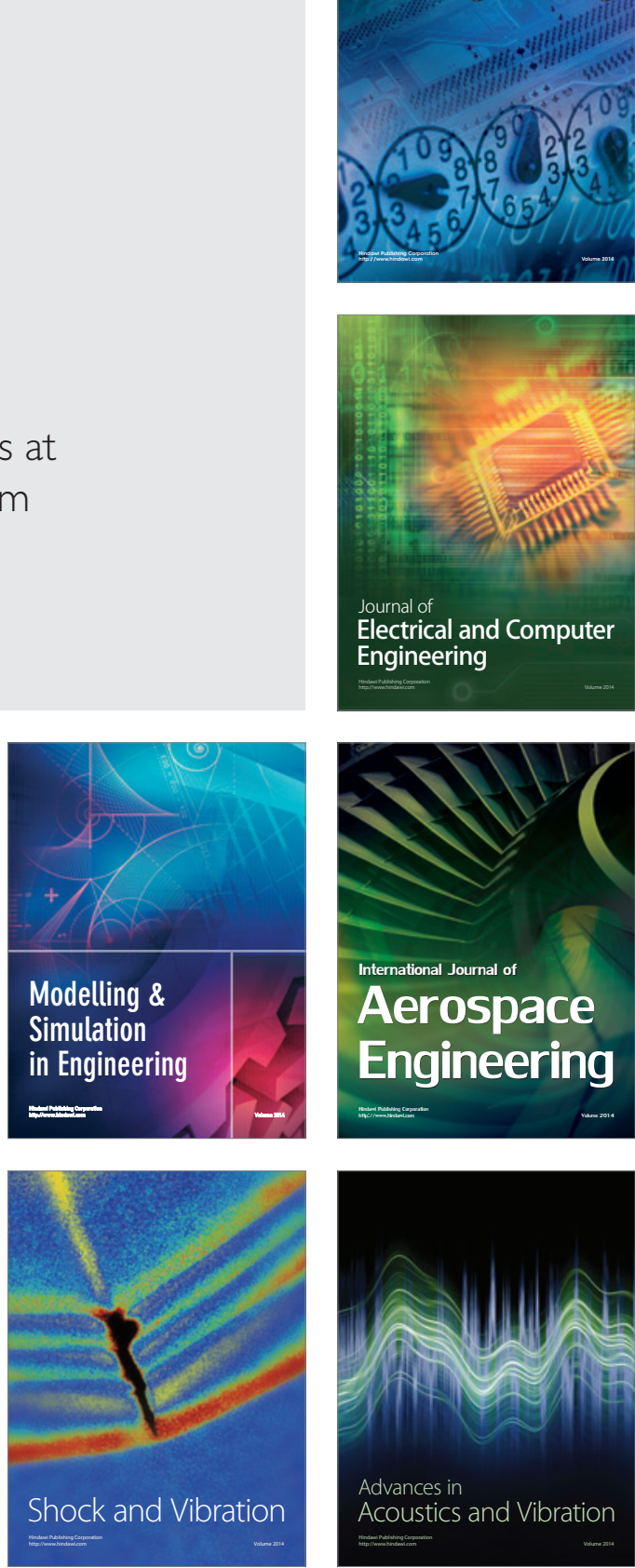